\title{
Causes of Hand Tingling in Visual Display Terminal Workers
}

\author{
Sein Oh, MD, Hyung Kuk Kim, MD, Jehwan Kwak, MD, Taikon Kim, MD, Seong Ho Jang, MD, \\ Kyu Hoon Lee, MD, Mi Jung Kim, MD, Si-Bog Park, MD, Seung Hoon Han, MD \\ Department of Rehabilitation Medicine, Hanyang University College of Medicine, Seoul, Korea
}

Objective To offer the basic data about the causes and distribution of hand tingling, symptoms and physical findings, and pressure pain threshold in desk workers.

Methods Five physiatrists participated in the screening test composed of history and physical examination. A total of 876 desk workers were evaluated and of them 37 subjects with hand tingling were selected. For further analyzing, detailed history taking and meticulous physical examination were taken. Pressure pain threshold (PPT) at the infraspinatus, upper trapezius, flexor carpi radialis, rhomboideus, and flexor pollicis longus were examined. PPT measurements were repeated three times with two minute intervals by a pressure algometer. Electrodiagnostic study was done to detect potential neurologic abnormalities.

Results The causes of hand tingling in order of frequency were: myofascial pain syndrome, $68 \%$; cervical radiculopathy, $27 \%$; rotator cuff syndrome, $11 \%$; tenosynovitis, $8 \%$; and carpal tunnel syndrome, $5 \%$. The location of trigger points in the myofascial pain syndrome, which were proven to evoke a tingling sensation to the hand in order of frequency were: infraspinatus, $65.4 \%$; upper trapezius, $57.7 \%$; flexor carpi radialis, $38.5 \%$; rhomboideus $15.4 \%$; and flexor pollicis longus $11.5 \%$. The PPT of the affected side was significantly lower than that of the unaffected side in myofascial pain syndrome $(\mathrm{p}<0.05)$.

Conclusion The most common cause of hand tingling in desk workers was myofascial pain syndrome rather than carpal tunnel syndrome. Common trigger points to evoke hand tingling were in the infraspinatus and upper trapezius.

Keywords Hand tingling, Myofascial pain syndromes, VDT workers, Pressure pain threshold

Received July 26, 2012; Accepted October 18, 2012

Corresponding author: Seung Hoon Han

Department of Rehabilitation Medicine, Hanyang University Guri Hospital, 153 Gyeongchun-ro, Guri 471-701, Korea

Tel: +82-31-560-2380, Fax: +82-31-564-4654, E-mail: stephan72@ hanmail.net

(c) This is an open-access article distributed under the terms of the Creative Commons Attribution Non-Commercial License (http://creativecommons. org/licenses/by-nc/3.0) which permits unrestricted noncommercial use, distribution, and reproduction in any medium, provided the original work is properly cited.

Copyright $\odot 2013$ by Korean Academy of Rehabilitation Medicine

\section{INTRODUCTION}

The definition of the World Health Organization on work-related musculoskeletal disorders (WRMSDs) was focused on the disease creation due to repetitive use, which is the disorder on the muscle, tendon, peripheral nerves, and blood vascular system that can be created or advanced by the repetitive and consistent use of the physical body. The National Institute of Occupational Safety and Health defined as a concept including the appearance of the symptoms related with the occupa- 
tion i.e., 'the case of consistency of more than a week or appearance more than once per month throughout the year of the symptoms of pain, stiffness, burning sensation, and tingling on the neck, shoulders, elbow joint, forearms, hands wrist while the person who had not been injured from the accident is working involved in current occupation' [1].

As it was said, work-related musculoskeletal system disorders were referred as shoulder-arm-neck syndrome or repetitive strain injury because they are created from repetitive motion or cumulative traumatic disorders due to the accumulation of damages, but its terminology was clarified [2,3] as WMSDs including low back pain and lower limbs.

The office workers in modern society have been involved in working on the visual display terminal (VDT). According to Ohara et al. [4] and Onishi et al. [5], VDT working is a task requiring the maintaining of consistent posture mainly on the upper limbs and the mental stress which may result in the disorders of pain, asthenia, edema, and paresthesia on the musculoskeletal system such as the neck, shoulders, arms, and hands. In addition, it had been reported that the causes of WRMSD are various and its individual difference is big and similar with chronic regressive diseases in its features [6].

Hand tingling is an abnormal sense such as the numbness and tingling which can be experienced frequently in the first consultation. The neuropathy on the carpal tunnel is doubted and evaluated usually when hand tingling is appealed, but the frequency of carpal tunnel syndrome has not been reported as a cause for hand tingling. Especially, the study on the frequency and reason of hand tingling regarding work-related musculoskeletal system disease for office workers, the study subjects for this survey are very rare.

Accordingly, this study surveyed the reason, frequency and distribution of hand tingling which confront office workers frequently through listening on the disease history in detail, physiochemical examination, and electrodiagnostic examination and this study will be a help toward the diagnosis and treatment of hand tingling for office workers in the future.

\section{MATERIALS AND METHODS}

Five physiatrists with more than 10 years of experience participated in the survey for 876 office workers who are working in a government-affiliated institute. The questionnaire survey on the general characteristics of all subjects was performed and 5 physiatrists examined the parts and the features of hand tingling through questioning, and muscle weakness, muscular dystrophy, and paresthesia were examined and the physical examination such as Phalen's test, reversed Phalen's test, and Tinel's test were performed. Since there were many cases not detailing the specific part exactly, additional examination on hand tingling was performed in the rehabilitation medicine department of tertiary university hospital in case of consistent hand tingling for at least 3 months while appealing the general hand tingling symptom including the palm, dorsum of the hand and fingers.

It was impossible to set the control group without symptoms because of the characteristics for the largescale musculoskeletal system disease examination project. Therefore, 37 individuals with symptoms in one side only were adopted as research subjects to set the healthy side without hand tingling as a control group in the same patients. The physiochemical examination, visual analogue scale (VAS) for hand tingling evaluation, ultrasonic examination and electrophysiologic study were performed, and the pressure pain threshold was made in case of the existence of a trigger point.

The criteria of examination on each of the work-related musculoskeletal system diseases estimated as a cause of hand tingling are as follows. There are clinical symptoms of muscular weakness, paresthesia, and restriction on the movement range of joint and pressure pain. The case of confirmed rotator cuff injury in the ultrasonic examination as a positive opinion in the evoked tests of Neer's test, Hawkin's test and the empty can test was diagnosed as rotator cuff syndrome. In addition, there was muscular weakness, paresthesia, pain in joint movement, restriction on the joint movement range, pressure pain on the tendon and a positive sign of Finkelstein's test. The cases of confirmed edema and injury on the tendon by ultrasonic examination were examined as tenosynovitis. There were the clinical symptoms such as pain in the cervical vertebral portion, radicular pain, muscular weakness and paresthesia and they were examined through the electrophysiologic study.

Carpal tunnel syndrome was diagnosed by performing the electrophysiologic study together with the clinical 
symptoms of muscular weakness, muscular dystrophy and paresthesia, Phalen's test, reversed Phalen's test, and Tinel's test. In case of confirmed pressure pain and a taut band by stimulating the muscle after exclusion of all above causes, the pain on the upper limb and referred pain were appeared and the appearance of the restriction on the movement range of the joint was diagnosed as myofascial pain syndrome. In case of suspicion as myofascial pain syndrome in the first examination, 13 muscles such as the cervical paraspinalis, levator scapulae, supraspinatus, teres minor, pectoralis minor, flexor carpi radialis (FCR), extensor indicis proprius, upper trapezius, rhomboideus, infraspinatus, pectoralis major, and brachioradialis, extensor carpi radialis were checked. In case of suspicion of hand tingling, the muscles on the forearm such as the flexor pollicis longus were checked.

The authors measured the pressure pain threshold on two muscles of the trapezius and rhomboideus which were appealed as the places for hand tingling by the subjects and they were compared. The pressure pain threshold was measured by using the digital pressure pain machine FDX25 Force Gauge (Wagner Instrument, Richmond, TX, USA) and the measuring method is as follows. The vertical force was applied to the examining part of examinees with the measuring device and they were instructed to sound "Ah" or raise the hand when the pain was felt by the pressing feeling on the examination part while the pressure was increased in constant speed of 1 $\mathrm{kg} / \mathrm{cm}^{2}$. It was measured 3 times successively by checking 10 muscles and taking a rest for 5 minutes. This study was analyzed by using SPSS ver. 18.0 (SPSS Inc., Chicago, IL, USA). The independent t-test was used for general technical statistics and VAS score comparison between male and female, the Pearson correlation analysis was used for

Table 1. General characteristics of subjects

\begin{tabular}{|lc|}
\hline \multicolumn{1}{c}{ Characteristic } & Value \\
\hline Male:female & $20: 17$ \\
\hline Age $(\mathrm{yr})$ & $41.0 \pm 6.5$ \\
\hline Height $(\mathrm{cm})$ & $167.0 \pm 7.2$ \\
\hline Weight $(\mathrm{kg})$ & $63.5 \pm 11.2$ \\
\hline Computer time (hr/day) & $7.3 \pm 2.0$ \\
\hline Visual analogue scale score & $4.0 \pm 1.9$ \\
\hline Male & $3.5 \pm 1.6$ \\
\hline Female & $4.6 \pm 2.1$ \\
\hline
\end{tabular}

Values are presented as mean \pm standard deviation. the for the correlation between computer using time and VAS score, the paired t-test was adopted for the comparison of pressure pain threshold between the unaffected side and the affected side, and the generalized estimation equation of general linear model was used for the difference in the average threshold on the affected side muscles.

\section{RESULTS}

\section{General features of the subjects}

People who appealed the hand tingling totaled 37 out of 876 office workers and the prevalence of hand tingling was $4.2 \%$. The average age was 41 years and males were 20 and females were 17 . The average time spend working on a computer during the day was 7.3 hours and the VAS score for hand tingling was 4.0 on average. The average VAS score was higher than males, but there was no statistically significant difference (Table 1). The correlation between computer working hours and the correlation with the VAS score was analyzed, but it was not statistically significant.

\section{Causes of hand tingling}

The causes of hand tingling decided with the basis of the physiochemical test, disease history listening and electrophysiologic study were 25 persons $(68 \%)$ of myofascial pain syndrome, the next was cervical radiculopathy, rotator cuff syndrome, tenosynovitis, and carpal tunnel syndrome in order (Table 2). The parts for radiculopathy was 1 person of $\mathrm{C} 5$ radiculopathy, 5 persons of $\mathrm{C} 6$ radiculopathy, 2 persons of $\mathrm{C} 7$ radiculopathy, and 2 persons of $\mathrm{C} 8$ radiculopathy. The average VAS for the subjects of myofascial pain syndrome was $3.9 \pm 2.2$ points, $2.2 \pm 0.6$ points for cervical radiculopathy, $3.0 \pm 1.8$ points for rotator cuff syndrome, $3.7 \pm 3.0$ points for tenosynovitis, and $5.0 \pm 0.0$ points for carpal tunnel syndrome.

Table 2. Causes of hand tingling in visual display terminal workers $(n=37)$

\begin{tabular}{lc}
\hline \multicolumn{1}{c}{ Cause } & No. (\%) \\
\hline Myofascial pain syndrome & $25(68)$ \\
\hline Cervical radiculopathy & $10(27)$ \\
\hline Rotator cuff syndrome & $4(11)$ \\
\hline Tenosynovitis & $3(8)$ \\
\hline Carpal tunnel syndrome & $2(5)$ \\
\hline
\end{tabular}


Four persons accompanied with cervical radiculopathy, 2 persons accompanied with tenosynovitis, and 1 person accompanied with the rotator cuff syndrome out of 25 subjects who were diagnosed with myofascial pain syndrome. More than 2 diseases were accompanied to 7 subjects.

The distribution of myofascial trigger points appealed by the subjects

The biggest frequency of myofascial trigger points appealed by the subjects was infraspinatus in $65.4 \%$. The next were trapezius, FCR, rhomboideus, and pollicis longus in order. The results for the case of existence of myofascial trigger points at 1 muscle and the cases accompanied with other muscles were the same with Table 3.

The analysis on the pressure pain threshold

The infraspinatus on the right was $5.2 \pm 1.9\left(\mathrm{~kg} / \mathrm{cm}^{2}\right)$ which was the highest in the pressure pain threshold survey of the subjects. When the pressure pain threshold of the affected side and unaffected side was compared with 25 persons corresponding to the myofascial pain syndrome which was surveyed as the most frequent reason for hand tingling, the pressure pain threshold was lower in the affected side than the unaffected side (Table 4). But when the pressure pain threshold for 5 sick sides of the muscles was compared on 5 muscles out of 25 persons of myofascial pain syndrome, it did not show the significant difference.

\section{DISCUSSION}

Hand tingling is one of the symptoms which is faced most frequently in the 1st consultation and the hand tingling of office workers who are spending the majority of working hours on the computer was one of the most fre-

Table 3. Distribution of trigger points in patients with hand tingling

\begin{tabular}{lccr}
\hline \multicolumn{1}{c}{ Muscle } & Solitary & With others & Total (\%) \\
\hline Infraspinatus & 9 & 23 & $32(65.4)$ \\
Trapezius & 7 & 21 & $28(57.7)$ \\
Flexor carpi radialis & 4 & 15 & $19(38.5)$ \\
Rhomboideus & 1 & 6 & $7(15.4)$ \\
Flexor pollicis longus & 1 & 4 & $5(11.5)$ \\
\hline
\end{tabular}

quent musculoskeletal diseases. However, it is not easy to diagnose after excluding many causes because the causes of hand tingling are varied with vascular diseases, inflammation, tumor, trauma, endocrine, and nerve system disease [7-9]. The myofascial pain syndrome was the biggest cause of hand tingling on the VDT workers in this study. The next, in order, was cervical radiculopathy, rotator cuff syndrome, carpal tunnel syndrome, and tenosynovitis. The different result where hand tingling is caused by the damage on the nerve was appeared.

The pain of the dermatome corresponding to the spinal segment of myofascial trigger points can be a referred pain because the myofascial pain syndrome is a local pain syndrome which accompanies the myofascial trigger points and it was known that paresthesia can be induced [10]. The cases of the referred pain of the trapezius appearing to the fingers are rare in the previous reports and it was reported [11], that the referred pain was created to the wrist or fingers by the myofascial trigger points on the subscapularis, infraspinatus, teres major muscle, and serratus anterior. It was surveyed in this study that its frequency was as similar not only in the infraspinatus but also in the trapezius. It strongly implicates that the possibility influencing of myofascial pain syndrome at the trapezius on hand tingling actually. However, the possibility of hand tingling occurring is high due to the existence of myofascial trigger points simultaneously on the trapezius and other muscles. However, the hand tingling was appeared on 7 subjects with myofascial trigger points on the trapezius and it implies that myofascial trigger points contributed directly on the creation of hand tingling in the trapezius. In addition, the result showed the implication that hand tingling can be made in the rhomboideus which is known as no radiating to the hands as the case

Table 4. Comparison of pressure pain threshold between affected and unaffected sides in myofascial pain syndrome $(\mathrm{n}=25)$

\begin{tabular}{|c|c|c|}
\hline Muscle & $\begin{array}{l}\text { Affected } \\
\left(\mathrm{kg} / \mathrm{cm}^{2}\right)\end{array}$ & $\begin{array}{c}\text { Unaffected } \\
\left(\mathrm{kg} / \mathrm{cm}^{2}\right)\end{array}$ \\
\hline Infraspinatus & $3.8 \pm 1.5^{\mathrm{a})}$ & $4.2 \pm 1.6$ \\
\hline Trapezius & $4.2 \pm 1.3^{\mathrm{a})}$ & $4.5 \pm 1.3$ \\
\hline Flexor carpi radialis & $4.3 \pm 1.5^{\mathrm{a})}$ & $4.8 \pm 1.7$ \\
\hline Rhomboideus & $4.5 \pm 1.4^{\mathrm{a})}$ & $4.8 \pm 1.4$ \\
\hline Flexor pollicis longus & $4.3 \pm 1.5^{\mathrm{a})}$ & $4.8 \pm 1.5$ \\
\hline
\end{tabular}


of trapezius even though the frequency was slightly lower than the trapezius. Also, it was reported [12] that the infraspinatus creates the referred pain to the shoulder, the lateral aspect of the arm and forearm, radial aspect of the hand and the fingers, and FCR creates the referred pain to the radial aspect of the anterior forearm, the volar wrist and the palm, and flexor pollicis longus creates the referred pain to the volar aspect of the thumb and its tip. It was confirmed that there are many cases of myofascial pain syndrome on the above muscles. It is considered that clear results can be obtained from the aspects creating the hand tingling by the myofascial trigger points when the treatment on the myofascial trigger points in each muscle is performed and the study of tracing and observing the changes of hand tingling are progressed based on the results of this study in the future.

Measuring the pressure pain on the corresponding muscle out of the diagnosing methods for myofascial pain is an important method. The reliability depending on the measuring person or measuring frequency was comparatively high and it was reported that very high reliability from 0.9 to 0.95 appeared with the intraclass coefficient according to the studies by Chung et al. [13] and Chesterton et al. [14]. The significant difference was shown in this study when the pressure pain threshold on the affected side and the unaffected side is compared for the subjects. It was already an expected result before the study because of the characteristics of the myofascial pain syndrome. However, the significant difference was not shown when the pressure pain threshold was compared to the 5 muscles on the sick side for 25 persons with myofascial pain syndrome. Actually, the above results may be derived from the less subjects of this study, but active and potential myofascial trigger points are distributed evenly on every muscle for VDT workers and it means that the pressure pain threshold on the muscles not appealing the clinical symptoms is similar with the pressure pain threshold on the muscle appealing the symptom. These results recognize the existence of the potential myofascial trigger points not only the active myofascial trigger points in the high risk group of disease creation for myofascial pain syndrome like the workers on VDT and it implies that the controlling of it is very important.

Cervical radiculopathy becomes an important cause of neck pain and disorder. The patients with cervical ra- diculopathy appeal the neck pain, paresthesia, and the radicular pain. According to the previous studies, the dermatome pain appeared more frequently in the $\mathrm{C} 4$ level (60\%) than in the C6 level (35\%) and the C7 level $(34.2 \%)$ [15]. It was reported that the hypoesthesia appeared in $1 / 3$ of the patients and muscle weakness in the upper limb was 15. It was reported that C7 (range, 39.3\% to $46.3 \%$ ) and C6 (range, $17.6 \%$ to $42.6 \%$ ) were the neuromuscles of disease creation $[15,16]$. Ten out of 37 subjects (27\%) of 1 C5 radiculopathy, 5 C6 radiculopathy and 2 C7 radiculopathy and 2 C8 radiculopathy were diagnosed as cervical radiculopathy and it was the second highest frequency only to myofascial pain syndrome. Generally, according to the dermatome, the $\mathrm{C} 6, \mathrm{C} 7$, and $\mathrm{C} 8$ radiculopathy can demonstrate paresthesia on the hands, but it was known that $\mathrm{C} 5$ radiculopathy does not create paresthesia on the hands. There were myofascial trigger points on the infraspinatus and trapezius not only on the C5 radiculopathy for 1 subject who was diagonosed as radiculopathy but also on the infraspinatus and trapezius. Therefore, the authors could not discern the cause of the hand tingling clearly, but it is considered that myofascial pain syndrome made a bigger contribution on the creation of hand tingling than C5 radiculopathy. Nevertheless, the result of this study that cervical radiculopathy showed frequency secondly only to myofascial pain syndrome implies that recognizing and diagnosing cervical radiculopathy are essential besides the myofascial pain syndrome.

Rotator cuff syndrome pain is created from the distributed pain which usually appears abruptly and it expands to the arms and shoulders. The motion of lifting up the arms above the head worsens the pain and the pain becomes more severe in the night sometimes and disturbs sleep. Far advanced cases may cause the weakness or impossibility in lifting up the arms to the front and pronation [17]. There was the rotator cuff syndrome in 4 subjects which is $11 \%$ of subjects appealing the hand tingling in this study and the myofascial pain syndrome was accompanied in 1 subject out of these. There is a restriction of too few subjects in this study to say that the rotator cuff syndrome was the cause of creating the hand tingling, but the study result that the rotator cuff syndrome and hand tingling were accompanied in the state of excluding the other reasons through precise physiochemical examination and the electromyography by the skilled examiners 
implies that the rotator cuff syndrome may create hand tingling.

Repetitive work requires maintaining specific posture while the specific muscles and tendons are used consistently and it damages on the soft tissue and can create restriction on the pain and movement due to the creation of inflammation. In addition, there was a report that pressure on the surrounded peripheral nerve may cause the pain, paresthesia and the weakness in the involved nerve distribution [18]. Three subjects with tenosynovitis who appealed the hand tingling without damage on the nerve through electrophysiologic study were found in this study. There is a possibility that only the tenosynovitis may not create the hand tingling because myofascial trigger points exist on the infraspinatus and trapezius in 1 out of 3 subjects, and 1 subject accompanies myofascial pain syndrome with existing myofascial trigger points on the infraspinatus and rhomboideus. However, the causes from other musculoskeletal systems besides the tenosynovitis in 1 subject of tenosynovitis were excluded, therefore, the authors decided that tenosynovitis is a cause of hand tingling. The authors made the literature study, but the studies related to this subject were not found. Therefore, the authors believe that tenosynovitis contributes a part of hand tingling creation though the mechanism of referred pain.

Carpal tunnel syndrome was the 5th cause of hand tingling in this study. Also, it may entail large treatment costs and cause the disorder [19] as it is a frequent disease in the work-related musculoskeletal system. Age, pregnancy, obesity, rheumatoid arthritis, gout, and hypothyroidism are well known risk factors [20]. The powerful and repetitive movement of hands and wrists, and the use of vibrational tools were known as the work-related risk factors [21]. Eventually, the prevalence of carpal tunnel syndrome in the occupation group with such risky factors related with work has a high correlation also. The prevalence of carpal tunnel syndrome in various occupation groups are varied from $0.6 \%$ to $61 \%$ [22]. The repetition, force, vibration, and excessive wrist posture are frequent risk factors related to work, but there was a study that VDT work is not exposed to such risk factors excessively. Silverstein et al. [21] reported that the risk of carpal tunnel syndrome creation did not increase greatly unless the hands are exposed to the powerful movement and vibration even though the repetitive motion was taken place for most VDT workers during typing. Viikari-Juntura and Silverstein [23] reported that the static posture on the vertebrate and upper limb appears on the VDT workers, but the wrist posture was not as serious since it was shown in other occupation groups.

Comparatively low frequency of carpal tunnel syndrome for the cause of hand tingling was shown in this study for the subjects of VDT workers as differently with the expectation of authors. There are many cases of treatment after evaluating the radiculopathy like carpal tunnel syndrome usually when the patients appeal hand tingling. But it is considered that the high frequency of myofascial pain syndrome, cervical radiculopathy, rotator cuff syndrome, and tenosynovitis besides carpal tunnel syndrome as causes of hand tingling of VDT workers in this study has a significant meaning clinically.

There are many previous studies related to the creation of the working environment like working hours and workrelated musculoskeletal system diseases and the level of seriousness. Knave et al. [24] reported the correlation between the daily VDT working hours of women and the appealing of musculoskeletal symptoms and Rossignol et al. [25] reported that the odds ratio of musculoskeletal symptoms were increased in VDT workers who are involved more than 7 hours a day when the workers using VDT and workers of no using VDT were compared. The working hours and the level of hand tingling were surveyed in this study, but it did not display the correlation. It is imagined that it is from the fact that most of the subjects of this study have similar VDT working hours and it is considered that the studies to survey the correlation with hand tingling for the diversified working hour groups are necessary.

With regard to the restrictions of this study, firstly, sufficient analysis was difficult depending on diseases because of the minimal amount of total subjects and subjects corresponding to each disease group. Secondly, in relation to the VDT work, the analysis on the internal diseases such as the other diseases which may cause hand tingling, for example, thyroid disease, electrolyte abnormalities, and avitaminosis was impossible because only neuromusculoskeletal system diseases were surveyed. Thirdly, 7 subjects exhibited myofascial pain syndrome out of the subjects who were diagnosed for cervical radiculopathy, tenosynovitis, and rotator cuff syndrome because of the work-related musculoskeletal 
system diseases and the precise analysis on the cause of hand tingling of the subject was difficult in this case. Fourthly, the possibility of creating the hand tingling was comparatively high on the muscles of forearms due to the mechanism of the referred pain because of its anatomical location. In addition, the possibility of hand tingling due to the trigger points on the other muscles in forearms was not completely excluded because the trigger points on 5 muscles in the forearms were evaluated in this study. Moreover, the exact aspects of hand tingling was not evaluated depending on each muscle due to the ambiguity on the expression of appealing the hand tingling by the subjects. Fifthly, it was necessary to observe the change on the symptoms of hand tingling before and after treating each disease in order to identify each neuromusculoskeletal system disease stated in this study as causes of hand tingling. However, the above study design was impossible because of the characteristics of this study which was made as part of a large scale examination project. In spite of said restrictions, this study is meaningful in that it provides the basic data on the hand tingling studied for work-related musculoskeletal system disease with 876 subjects of VDT workers who appeal the musculoskeletal system symptoms.

In conclusion, in case of appealing the hand tingling by office workers in this study, the myofascial pain syndrome was the most frequent cause and there were many cases of locating the myofascial trigger points at the muscles near to the shoulder such as the infraspinatus and trapezius. It is considered that the results from this study will be a meaningful basic data to the large scale examination project especially for the office workers who appeal the work-related musculoskeletal system disease and the related study thereto.

\section{CONFLICT OF INTEREST}

No potential conflict of interest relevant to this article was reported.

\section{REFERENCES}

1. Kim DQ, Cho SH, Han TR, Kwon HJ, Ha M, Paik NJ. The effect of VDT work on work-related musculoskeletal disorder. Korean J Occup Environ Med 1998;10: 524-33.
2. Armstrong TJ, Buckle P, Fine LJ, Hagberg M, Jonsson B, Kilbom A, et al. A conceptual model for work-related neck and upper-limb musculoskeletal disorders. Scand J Work Environ Health 1993;19:73-84.

3. Silverstein BA, Stetson DS, Keyserling WM, Fine LJ. Work-related musculoskeletal disorders: comparison of data sources for surveillance. Am J Ind Med 1997;31:600-8.

4. Ohara H, Nakagiri S, Itani T, Wake K, Aoyama H. Occupational health hazards resulting from elevated work rate situations. J Hum Ergol (Tokyo) 1976;5:17382.

5. Onishi N, Nomura H, Sakai K, Yamamoto T, Hirayama $\mathrm{K}$, Itani T. Shoulder muscle tenderness and physical features of female industrial workers. J Hum Ergol (Tokyo) 1976;5:87-102.

6. Bechtol CO. Grip test: the use of a dynamometer with adjustable handle spacings. J Bone Joint Surg Am 1954;36:820-4.

7. Collins RD. Differential diagnosis in primary care. 4th ed. Philadelphia: Lippincott Williams \& Wilkins; 2007.

8. Reading I, Walker-Bone K, Palmer KT, Cooper C, Coggon $\mathrm{D}$. Anatomic distribution of sensory symptoms in the hand and their relation to neck pain, psychosocial variables, and occupational activities. Am J Epidemiol 2003;157:524-30.

9. Sivan M, Venkateswaran B, Mullett H, Even T, Khan S, Copeland S, et al. Peripheral paresthesia in patients with subacromial impingement syndrome. Arch Orthop Trauma Surg 2007;127:609-12.

10. Yap EC. Myofascial pain: an overview. Ann Acad Med Singapore 2007;36:43-8.

11. Gerwin RD. Myofascial pain syndromes in the upper extremity. J Hand Ther 1997;10:130-6.

12. Simons DG. Hand and finger flexors in the forearm. In: Simons DG, Travell JG, Simons LS, editors. Travell \& Simons' myofascial pain and dysfunction: the trigger point manual. 2nd ed. Baltimore: Williams \& Wilkins; 1999. p. 753-73.

13. Chung SC, Um BY, Kim HS. Evaluation of pressure pain threshold in head and neck muscles by electronic algometer: intrarater and interrater reliability. Cranio 1992;10:28-34.

14. Chesterton LS, Sim J, Wright CC, Foster NE. Interrater reliability of algometry in measuring pressure pain thresholds in healthy humans, using multiple raters. 
Clin J Pain 2007;23:760-6.

15. Murphy DR, Hurwitz EL, Gregory A, Clary R. A nonsurgical approach to the management of patients with cervical radiculopathy: a prospective observational cohort study. J Manipulative Physiol Ther 2006;29:279-87.

16. Radhakrishnan K, Litchy WJ, O'Fallon WM, Kurland LT. Epidemiology of cervical radiculopathy: a population-based study from Rochester, Minnesota, 1976 through 1990. Brain 1994;117(Pt 2):325-35.

17. Gomoll AH, Katz JN, Warner JJ, Millett PJ. Rotator cuff disorders: recognition and management among patients with shoulder pain. Arthritis Rheum 2004;50:3751-61.

18. Nadler SF, Schuler S, Nadler JS. Cumulative trauma disorders. In: DeLisa JA, Gans BM, Walsh NE, editors. Physical medicine and rehabilitation: principles and practice. 4th ed. Philadelphia: Lippincott Williams \& Wilkins; 2005. p. 615-30.

19. Blanc PD, Faucett J, Kennedy JJ, Cisternas M, Yelin E. Self-reported carpal tunnel syndrome: predictors of work disability from the National Health Interview Survey Occupational Health Supplement. Am J Ind
Med 1996;30:362-8.

20. de Krom MC, Kester AD, Knipschild PG, Spaans F. Risk factors for carpal tunnel syndrome. Am J Epidemiol 1990;132:1102-10.

21. Silverstein BA, Fine LJ, Armstrong TJ. Occupational factors and carpal tunnel syndrome. Am J Ind Med 1987;11:343-58.

22. Hagberg M, Morgenstern H, Kelsh M. Impact of occupations and job tasks on the prevalence of carpal tunnel syndrome. Scand J Work Environ Health 1992;18:337-45.

23. Viikari-Juntura E, Silverstein B. Role of physical load factors in carpal tunnel syndrome. Scand J Work Environ Health 1999;25:163-85.

24. Knave BG, Wibom RI, Voss M, Hedstrom LD, Bergqvist UO. Work with video display terminals among office employees. I. Subjective symptoms and discomfort. Scand J Work Environ Health 1985;11:457-66.

25. Rossignol AM, Morse EP, Summers VM, Pagnotto LD. Video display terminal use and reported health symptoms among Massachusetts clerical workers. J Occup Med 1987;29:112-8. 